\title{
Life on a Tightrope: An Interpretive Phenomenological Analysis of Narratives of Coping With Academic Stress Among Filipino Medical Students
}

Elizabeth Aileen Garan-Giller, M.D. ${ }^{1}$,
Dominico Carlo S. Dator, M.D. ${ }^{1}$
Mart Blas Angelo P. Juan, M.D.'
Genevieve Anne R. Querubin, M.D. ${ }^{1}$,
Tiphanie P. Sevilla, M.D.'
Maria Minerva P. Calimag, M.D., Ph.D. ${ }^{1,2,3,4}$

\section{ABSTRACT}

Background Life in a medical school is stressful for just about every medical student. Academic stress in small doses heightens the energy and awareness, giving one that mood most refer to as "pumped up" or "wired". When the incremental progression of stress brought about by health and emotional factors compounded by social and financial problems, overwhelmingly surpasses one's ability to cope, it leads to feelings of being "burnt out" or "stressed out". It can have a negative impact on a medical student's cognitive and psychological functioning resulting in

$\triangle$ Maria Minerva P. Calimag

mpcalimag@ust.edu.ph

1 Faculty of Medicine and Surgery

2 The Graduate School

3 Research Center for the Health Sciences

4 Research Center for Social Science and Education University of Santo Tomas, Manila, Philippines poor academic performance. Each person has his or her own unique way of dealing with it; some may outwit pressure without a bad outcome, while others just simply succumb to it.

Purpose A vast majority of research on academic stress is centered on its contributing factors and how they affect other aspects of students' lives. Coping mechanisms and effective ways in dealing with stress have also been delved into, but none have dwelt on a study of the medical students' lived experience of academic stress. There was no study found in literature which examined and collectively characterized the different phases that medical students go through in coping with academic stress, hence the impetus to undertake this study. Anchored on the Transactional Model of coping with stress, this study was undertaken to answer the central question: How do Filipino medical students collectively characterize the phases they undergo in coping with the stresses in medical school? Design The methodological underpinnings of this study are based on phenomenology. The objective 
of Interpretive Phenomenological Analysis (IPA) is to understand how a particular phenomenon is constituted from the participant's perspective. It offers researchers the opportunity to learn from the insights of experts - the research participants themselves. The respondents' insights were gathered through narratives culled through a guided semi-structured questionnaire patterned after social networking sites, allowing the respondents to liberally exploit their voices and thoughts. Narrative accounts gathered focused on the medical student's daily activities, matters that precipitate anxiety, their views on stress, and methods of coping. Through cool and warm analyses, the narratives were ultimately subjected to phenomenological reduction.

Findings Fascinatingly, after subjecting the narratives to a thorough and comprehensive phenomenological analysis, six emergent themes surfaced which collectively characterized the phases our respondent medical students underwent in coping with academic stress: Self-effacement Phase (Sensing inner trepidation), Self-awareness Phase (Settling in new surroundings), Self-weariness Phase (Struggling through stress) Self-attentiveness Phase (Staying focused to survive), Self-equilibrium Phase (Sustaining a state of symmetry), and Self-mastery Phase (Striving towards sovereignty and satisfaction). The "Tightrope" is a representation that lucidly embodies these six themes.

Conclusion Our respondents have experienced substantial challenges in medicine: they surmounted their inner trepidation; settled and acclimatized to their new surroundings; gained the courage to outwit stress and struggles; fought to strive, survive and stay focused; learned to maintain a state of balance and symmetry; and finally lived up to a sense of sovereignty and self-satisfaction. It is just a matter of perspective and attitude that demarcates a victor from a slacker.

Keywords: Medical students, Stress, Coping, Filipino

\footnotetext{
"All that a man does outwardly is but the expression and completion of his inward thought. To work effectually, he must think clearly; to act nobly, he must think nobly. Intellectual force is a principal element of the soul's life, and should be proposed by every man as the principal end of his being."
}

Channing
In the words of Sadock et al. (2007), stress can be described as a circumstance that disturbs or is likely to disturb the normal physiological and psychological functioning of a person [1]. Asterita (1985) defined stress as a "perceived threat," the term incorporating both the stimulus (stressor) and the response (coping) [2]. Bisht (1980) has defined academic stress as a demand related to academic frustration, academic conflict, academic pressure and academic anxiety that taxes or exceeds the available internal or external resources as cognitively appreciated by the student involved [3]. Lal (2014) described academic stress as mental distress linked to some anticipated frustration brought about by academic failure or even an unawareness to the possibility of such a failure [4].

In small doses, academic stress heightens the energy and awareness; alerting the senses to be able to focus on the important things at hand. People refer to the experience of this type of stress as feeling "pumped" or "wired." Incremental progression of overwhelming stress, however, can surpass our ability to cope with it in a positive way. People often describe the feeling as being "burned out" or "stressed out". It is therefore important to find means to shift to positive and productive ways when dealing with stress.

Globally, studies have shown that medical students experience a high incidence of personal distress during their undergraduate medical education [5-44]. Many studies have shown that medical students are vulnerable to stress and anxiety because of academic challenges that are unique to the discipline such as stress over struggling to meet academic standards, time management worries, and concerns over grades. Additionally, dealing with illness, disease and dying can impose emotional burdens, while curricular demands can tax the physical and physiological stamina of the medical student, often leading to depression $[18,22-23,29-30]$ and substance abuse [39]. Along with this awareness had come the corresponding recognition that such stress may lead to a high incidence of impairment, particularly in their mastery of the academic curriculum. This can lead to mental distress and have a negative impact on cognitive functioning and learning [6]. In most medical schools, the prevailing environment is one of an authoritarian and rigid system that encourages competition rather than cooperation between students. Studies suggest that poor mental health among students during medical school usually persists through- 
out training. When stress becomes overwhelming, then it affects the physical and mental functioning, and consequently undermines performance.

Life in medicine is stressful for just about every medical student $[19,22,25]$. The transition from college to postgraduate studies brings about a number of adjustment problems to aspiring doctors. Everyone reacts to stress differently and have their own unique way of dealing with it. Some may handle pressure and anxiety and outwit it without a bad outcome, while others just simply succumb to it [18-23]. Every day, medical students come face-to-face with lectures, small group discussions, practical exams, quizzes and other school activities. Stress is apparently caused by many factors, and it is inevitable in the lives of students, whether they are in the first year medical proper or in clerkship [32, 37-38, 40-41]. Only the students themselves can assess their level of tolerance to stressful situations. There are various ways of coping with and treating stress, but the best treatment is to prevent getting into situations that are likely to depress your ability to cope. It may not be possible most of the time, and may generally be out of control.

This study construes the stressful experiences as person-environment transactions and herein utilizes the Transactional Model of Stress and Coping as the lens for examining the phenomenon of coping with stress in medical school. These transactions depend on the impact of the external stressor, mediated by the person's appraisal of the stressor and the social and cultural resources at his or her disposal [45-47].

Studies have only addressed the physiological and psychological dimensions of stress in the school setting, centered mostly on contributory factors affecting other aspects of the students' lives. No study was found in literature which examined and collectively characterized the different phases that medical students go through in coping with academic stress and while academic stress in medical school has been studied globally, none has been done among Filipino medical students. To address this gap, the present study was undertaken to answer the central question: How do medical students collectively characterize the phases they undergo in coping with the stresses in medical school? Against this backdrop, it is, therefore, the overarching goal of this study to capture the essence or the "Lebenswelt" of the phe- nomenon of coping with academic stress among Filipino medical students.

\section{METHODS}

\section{Design}

In this qualitative study, a narrative framework was used to explore how medical students characterize the phases they undergo in coping with the phenomenon of academic stress. As human beings, we interact socially through the stories that we tell about ourselves and others. Thus, the context of the study of this narrative is about how humans make sense of the world through their experiences. The participants are storytellers and characters in their own and other's stories. The narrative is a way of characterizing the human experience of a phenomenon. Stories are constructed to make sense of our lived experience through the organization of disparate elements into meaningful wholes. Narratives call the subject into being and serve to situate its experience in time. The central task is evident when it is grasped that the participants are both living their stories in an ongoing experiential text and telling their reflective stories in words. The participants are, at once, engaged in living, telling, retelling, and reliving stories [48].

The methodological underpinnings of this study are based on interpretive phenomenology. Participants' narratives were analyzed using Interpretive Phenomenological Analysis (IPA), which is particularly appropriate to address meanings and perspectives of research participants. The major concern of interpretive phenomenological analysis is to understand "how the everyday, inter-subjective world is constituted" from the participants' perspective [49-52]. Hence it offers researchers the opportunity to learn from the insights of experts - the research participants themselves. Husserl's [53] statements explain the basic philosophical assumption underlying this inquiry when he said, and I quote "we can only know what we experience." In the words of Rossman and Rallis [54], phenomenology is a tradition in German philosophy with a focus on the essence of the lived experience. Heidegger [55] further refined Husserl's thought into existential philosophy and hermeneutics. In hermeneutics (derived from the name of the Greek god Hermes, which means 'to interpret' or 'to make clear'), the IPA researcher engages in a dynamic process of com- 
prehending the mindset of the respondents, putting himself in their shoes, and through an interpretative meaning-making activity translates the experience into something that is readily comprehensible. In the present study, the researchers themselves are medical students and are researching the phenomenon from an emic perspective. Member checking or participant feedback procedure were done to validate the findings.

Those engaged in phenomenological research focus in-depth on the meaning of a particular aspect of experience assuming that through dialogue and reflection, the quintessential meaning of the experience will be revealed. Language is viewed as the primary symbol system through which meaning is both constructed and conveyed [56]. The purposes of phenomenological inquiry are to describe, interpret, and critically engage in self-reflection into the "world as a world" [57]. The major data source for this inner perspective was interviewing. Patton [58] stated the purpose of interviewing specifically as "to find out what is in and on someone else's mind", and that is exactly what the target of this phenomenological study focuses on, ie, how Filipino medical students characterize the phases they go through in coping with academic stress.

\section{Selection}

A purposive sample of 75 full-time medical students in the three didactic levels of medical school in a comprehensive Philippine University was recruited. The sampling frame used was an up-to-date list of officially registered medical students obtained from the Dean's office.

\section{Research Instrumentation}

Data were collected using written narrative responses guided by semi-structured interview questions designed to inquire about a medical student's daily activities, matters that precipitate anxiety and their views on academic stress. The questionnaires were prepared in a manner that simulated social networks and blogs, thus allowing the respondents to liberally exploit their voices and thoughts. The narratives of stories collected from the informants and observation reports made by researchers themselves constitute the 'data' for this particular research study. Explicitly and avowedly narrative accounts emphasize subjectivities and contextual circumstances and the way in which events are causally linked and given meaning by their connections.

This is where the noetic and noematic structure of consciousness takes into account - "the consciousness of something". All consciousness has two aspects: the process of experiencing or noesis, and the stable something which is experienced or noema. We may have certain accounts of knowledge about the phenomenon; however, these are just preconceptual knowledge, and we have yet to experience it. There is an experience of astonishment in which it is possible for us to come to the world with no knowledge or preconceptions in contrast to our everyday theoretical knowledge.

The questionnaire focused on the students' lived experience as they underwent coping with the stresses. There were other factors considered that focused on the culture in medical school that either increased or attenuated their burden. Probing questions were asked so that the students can elaborate on their feelings or the necessary constituents of these feelings or experiences. Additionally, it centered on what the existence of these feelings or experiences indicates concerning their very nature as medical students. This phenomenological inquiry attempted to identify, isolate, formalize and produce an analysis of narratives regarding the phenomenon of academic stress in medical school.

\section{Mode of Analysis}

Polkinghorne's schema was utilized whereby analysis of narratives refers to storytelling projects that are grounded on pragmatic reasoning [59-60]. These projects treat stories as 'data' and use 'analysis' to arrive at themes that hold across stories or on delineating types of stories and/or storylines. The study made use of phenomenological reduction after reading and rereading the text, drawing and listing the concepts or memoing and coding, followed by categorizing (cool analysis) and thematizing (warm analysis) in an affinity diagram.

When stories are used as data in research, the object of study is the text itself. The researcher looks at the text in search of various themes (either predetermined themes or themes drawn from the data itself). The researcher is typically an objective (or 
subjective) outsider, looking in on the text and analyzing it for themes akin to making generalizations in quantitative research.

\section{Memoing and Coding}

The researchers applied memoing by recording or listing reflective notes with regard to the collected data that is relevant to answering the study's research question. Researchers transcribed the notes and grouped them into meaningful analytical units. These meaningful analytical units of data were then coded with symbols or descriptive words. These processes of coding, in a reductionist manner, aided in the ease of review.

\section{Categorization: Cool Analysis}

After memoing and coding, the data were summarized and organized creating a master list of categories. This involved the process of enumeration and searching relationships in the data. The different codes were organized in such a way that different hierarchical levels and category systems were created and given names. Category names emerged from the researcher, participants or literature. These categories were mutually exclusive, sensitive to what are in the data and in effect, the answers to the research questions. The categories were then linked together in a meaningful way with the use of an affinity diagram to reduce the data and facilitate this process. An affinity diagram allows for the organization of large amounts of narrative data and to create categories based on the natural relationship between topics. Memos with similar ideas were posted together and at a distance from dissimilar ideas.

\section{Thematization: Warm Analysis}

Upon reviewing the categories, a series of themes emerged. Emerging themes were organized into an affinity diagram, analyzed and their discourse dissected, thus determining how the participants variedly interpreted the phrase "coping with stresses in medicine" in their context.

For the purpose of this study, either abstract or conceptual categorization scheme was used. Data, such as metaphors among different student narratives were broken into segments and classified under a certain category that allowed efficient comparison. Comparison of similarities and dissimilarities allowed the interpretation of depth and meaning and type of phenomena reflected among the written metaphors or narratives.

Results were interpreted through the method of analyzing short reflected and written narratives made by the students on their perception of stress and their life as a medical student. Since this study of narrative seems to promise change, forcing sciences to develop new theories and new methods, particularly ways of talking about life and self in medicine as perceived by the very unit that makes a medical student body in the university [61].

The narrative framework in research as described by Nygren \& Blom [62] is an approach where interviewees are asked to reflect and then write down (short) narratives instead of telling them orally, which is a significantly different but complementary method. In the present study, the respondents were asked to write down their story of academic stress and then make an initial interpretation of what they have written. The researchers assumed that the respondents' written narratives constitute an interpretative step that impacts the quality of data for the analyst in a positive way. Written narratives produced by a homogenous group (as in this case) provided a more direct focus on the respondents' way of defining and understanding a phenomenon.

Since this address to a narrative aimed to extend analyses to research regarding students and their experiences in medicine, not only did it bring structures of language to possibilities of behavioral analysis but extended or rather focused on the context of every individual phrase, accounts and reflections of medical students perceiving life in medicine as a unit.

\section{Ethical Consideration}

This study received approval of the university's institutional review board. An informed consent letter was made inviting participants to take part in this study and be notified that their participation is completely voluntary. Further appraisal was done regarding the purpose, procedure, benefits, and risks of the research study with great emphasis on the voluntary nature of research participation where they are free to terminate their involvement in the study at any point. Participants were likewise informed that their responses will be strictly confidential and the data will be reported only in the aggregate. 


\section{FINDINGS}

After subjecting the narratives to a thorough and comprehensive IPA, six emergent themes surfaced which collectively characterized the phases our respondents underwent in coping with academic stress in medical school. Interestingly, we found the "Tightrope" as a symbolic representation which aptly embodies these six themes.

\section{Self-effacement Phase: Sensing Inner Strife}

The participants invariably started their narratives by recalling one of the momentous events in their lives, which is the decision-making process of whether or not to go into medical school. They expressed incoherent thoughts of raging emotional excitement against a backdrop of uncertainty and apprehension. They verbalized fear about what lies ahead thinking that they might not be able to measure up to expectations.

"At first I'm kind of doubtful if this is the one for me."

"Sometimes I don't know what my goal in life is. What happens next? I just let it be."

"I know it is not easy, but I think I can handle it very well"

"I really want to be a doctor someday. You know that sweet taste of reward after paddling through all the hardships"

"Coupled with prayer, I believe that I can outwit all the hardship medicine brings. So, bring it on!"

\section{Self-awareness Phase: Settling in New Sur- roundings}

After conquering the hurdle of decision-making, our respondents finally moved on to a phase that marked the start of their career. At this point in time, everything was defined by novelty: a different institution, refreshing milieu and fresh new faces. The students became aware of how to regulate their bodily responses to the slightest peculiarities of their environment, defining what they called as the "adjustment phase," a phase characterized by striking shifts in responsibilities that affect all other aspects in their lives.
"It was tough, especially the first few weeks, because we were still in the period of adjustment"

"I have minimal social life now. I choose sleeping over going out with friends. My life mainly consists of school and academics."

"Everyday is a new struggle for me."

"I wasn't accustomed to sleeping very late everyday. But I'm starting to adjust now."

"I haven't completely adjusted to my classmates. Coming from a different school for pre-med, with a totally different atmosphere and culture, it's tough to go about around these people"

Self-weariness Phase: Struggling Through the Stressors

The experience of medical students likewise resonated with feelings of overwhelming stress and constant struggle. Stress is precipitated by various factors: inner struggles, family expectations, workload, and other responsibilities.

"It's difficult and scary in such a way that I've been pressuring myself to get good, high grades in order to maintain my scholarship. Being the only doctor in the whole clan, I fear of getting disappointed if I don't become successful as what my relatives expect me to be."

"It's quite stressful when I study so hard only to get a low grade; Sometimes, no matter how much effort you give into a particular goal, it's not just good enough"

"It is stressful when people don't do their jobs in group-related activities like reporting"

"Life as a student in medicine is busy, hard, long and tiring. Some things just couldn't fit in a day, so other things must be sacrificed. But really, the studying part is easy, only if we had ample of time" 
"My family can be very demanding of bonding time even when there's just no non-academic time to spare"

\section{Self-attentiveness Phase: Staying Focused to Survive}

Life in medicine is guarded by a few rules: never look back, never look down and never get ahead of yourself, similar to walking the tightrope. Yesterday is history and it can no longer be undone, tomorrow lies in the future and it is yet to unravel, what is most important is to pay attention to the present and make the most out of it. Staying focused is an inner battle that one needs to live out, but it can also be promoted or deterred by external factors.

"Being a medical student requires a lot of perseverance and hard work. One cannot be lazy or else you suffer and fail"

"I think positive and pray. I don't like getting stressed over something that has happened already. I can't do anything about it anymore"

"There are times when I feel motivated to study, but there are also instances when it is difficult to start studying especially during weekends. What keeps me to continue studying are my parents who sacrificed a lot, my classmates who make me happy most of the time, and my future in this field"

"With my focus and passion in accomplishing things, I know I can achieve greater heights"

\section{Self-equilibrium Phase: Sustaining a State of Symmetry}

One must find his center of gravity. A good play of balance is the key to coping with the struggles in medicine.

"When I'm stressed, I eat. I buy junk foods like "Chippy" and coke zero, go home, and watch TV. I even date myself in the movie house, of course with my burger (from Burger King) and coke zero; window shopping with family and friends, dancing, singing, facebooking, and sleeping"

\begin{abstract}
"Being able to balance academics with extracurricular activities is just a matter of time management"

"I take the time off, even for just an hour or two, not worrying about school-related stuff"
\end{abstract}

"What matters most is the balance between medicine and other aspects of life. I escape from all the stresses by spending time out of Manila. I watch TV, listen to music, eat good food, read a good book, and spend time with friends"

"I make sure I get enough sleep in order to be functional the next day"

\section{Self-mastery Phase: Striving Towards Sover- eignty and Satisfaction}

Our respondents pride themselves with their ability to master the art of multitasking. Self-mastery brings about a sense of self-satisfaction. It is the integration of 3 entities - balance, rhythm and focus: balancing work and rest, timely rhythm of accomplishing one's errands and the depth of concentration one submits in executing a task. One acquires that feeling of self-satisfaction in knowing that one is able to conquer new objectives with skillful execution and humble acceptance of failures.

"It's like a roller coaster! Sometimes you're up, sometimes you're down. Don't let it get to you. Remember that you are the master of your fate"

"If you come to think of it, medicine really is overwhelming. But it is how you view stress that defines you and demarcates you from the rest"

"I seldom let bad vibes and stresses get the best of me. If I fall, I get sad; I shrug it off and get up again"

"In order to appreciate and enjoy medicine, you need to see it in a different light"

"I love to learn new stuff, especially if I get to apply it in experience and practice. Practice makes perfect." 


\section{DISCUSSION}

\section{Self-effacement Phase}

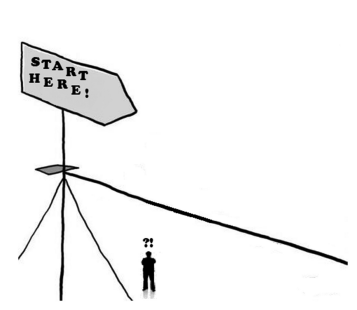

Our respondents were once in a phase where they felt alone and utterly clueless about how, when, or where to start. Life in Medicine is like walking a tightrope. Making a strenuous climb to the summit is but first of the many series of chronological events leading to their goal. This is the point where they go into quiet introspection, dissecting their thoughts and inner desires, and asking themselves, "Am I ready to conquer my fear?" According to a case study by Levine [63], medical students often experience uncertainty and apprehension around career planning, and many seek advice during the process. The medical student is at crossroads and wondering, "Is medicine right for me, and am I right for medicine?" A student's final decision represents a complex cognitive and emotional process that takes into account multiple contributing factors. The climb is not the starting point. It is merely an obstacle set to surmount the "inner trepidation" before actually reaching the summit, the official START. Before stepping into a medical institution, the students get overwhelmed by mixed emotions. There's that irrational unbridled joy, a thrilled feeling which sprang from a strong desire to finally become a medical student, or a feeling clouded with doubt and fear. "Is this as good as it is ever going to get? Am I ready to become a medical student? Is this what I really want?" These are the various environmental filters that the medical student needs to focus on. Medical students who are on their way to becoming the first physicians in the family face the fear of the unknown. The biggest hurdles for them are their fear of the unknown, and of being alone with no one to fall back on. Medical students who have physician parents felt the need to measure up to parents who are successful physicians.

\section{Self-awareness Phase}

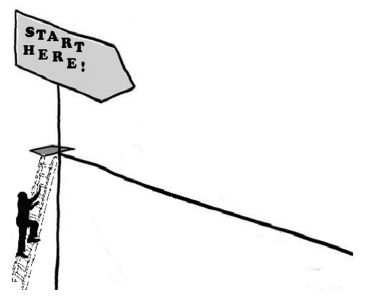

A sudden strike of awareness reels them from their reveries. This is the point of realization that there has got to be more to life than what they originally thought. Swallowing their fears, they climb towards the summit, one hand over the other, one step at a time, and finally conquering it! They are freshmen off to a starting point in medicine life.

One must try to become accustomed to the new surroundings. Now, how to start? "Tightrope walkers live by a few rules. Never look down. Hold your arms out for balance. Do not wait for the rope to stop wobbling before you take another step. And then there is this one: Practice standing at first. When you are able to do so without wobbling too much, take a step, stand again, take a step, stand again, until you reach the end of the rope." [64] In a wire act, the rope is slightly springy and taut so that it can launch funambulists (tightrope walkers) into the air to perform balancing acts. The tightrope must have the right amount of tension, meaning it cannot be too slack to cause too much wobbling or too taut to allow it to break. Now it all depends on how the respondents cross the tightrope. Suspended in the air like a funambulist, one must start with one foot forward, adjusting to the slightest bobbing of the rope, and then takes a second step, and standstill. This is the period of adjustment when our respondents become aware of how to regulate their bodily responses to the slightest peculiarities of their environment. Some would claim that they were not accustomed to the sudden change in sleeping habits or an unexpected plummet in their social lives. These imposing shifts of responsibilities now mainly consist of school and academics. It is only a matter of time that one gets acquainted with the change in environment and gradually progresses further to an established level.

\section{Self-weariness Phase}

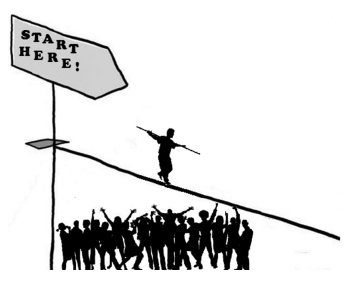

Medical students become mindful over their balance that, like a funambulist, they hastily look down at their feet and become daunted by the altitude. Inadvertently, they gaze upon the crowd of 
spectators cheering their name. These spectators are their family and friends. They are the ones encouraging them to conquer medicine's daily battles, giving that burst of motivation to cheer them on. Social support and attention to interpersonal relationships are important in buffering the impact of stress. These cheers prod them forward and give them the drive to exert strenuous efforts toward their goal.

The reverberating cheers grow louder and louder, turning into a distraction, a noise that persistently blares in the background. All of a sudden, it becomes crowded, hectic,

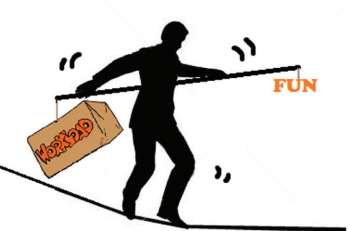
and frenzy. In the Transactional Model of coping with stress, this phase involves the primary appraisal of one's situation, that is, whether to consider the stressors as irrelevant, as dangerous, or in a positive light so as to overcome the stressors. A qualitative study by Jaykaran [33] summed that "An important issue was over expectation from themselves and parental pressure to perform better. The competition becomes tough. When a student cannot get good marks or high ranks, it becomes a source of stress." Low scores and failing grades evoke negative thoughts and feelings that can precipitate stress. In a multi-institutional study done by Dyrbye [31], approximately $11 \%$ of students have serious thoughts of dropping out of medical school each year. Burnout seems to be associated with an increased likelihood of serious thoughts of dropping out even in the absence of depression. On the basis of their responses, medical students likewise conveyed their feelings on the overwhelming workload: "Life as a student in medicine is busy, hard, long and tiring. Some things just couldn't fit in a day, so other things must be sacrificed. But really, the studying part is easy, only if we had ample of time".

\section{Self-attentiveness Phase}

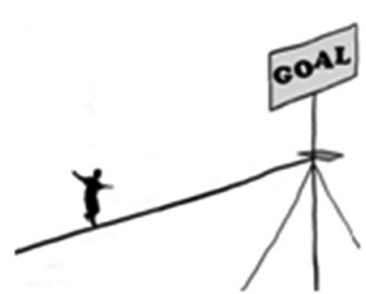

Like a tightrope, life in medicine is also guarded by a few rules: never look back, never look down and never get ahead of yourself. Most of our respondents tend to look back and regret over yesterday's mistakes, like pondering on the answers they changed on a previous quiz which turned out right. Seldom do they realize that dwelling on the past would get them nowhere but slacking in stagnant waters. They tend to prod themselves too hard trying to get ahead of time, and then end up in a state of unnecessary anxiety over tomorrow's problems. They get frefful of tomorrow's reports, or the quizzes set the next day, and even the papers due next week. They fail to realize that what's most important is to slowly tackle it one step at a time. Yesterday is history and it can no longer be undone, tomorrow lies in the future and it is yet to unravel, what is most important is to pay attention to the present and make the most out of it. In the Transactional Model of coping with stress, the Self-attentiveness Phase is the secondary appraisal phase whereby medical students muster all their competencies to cope with their life goal to finish medicine. Focus is the key.

\section{Self-equilibrium Phase}

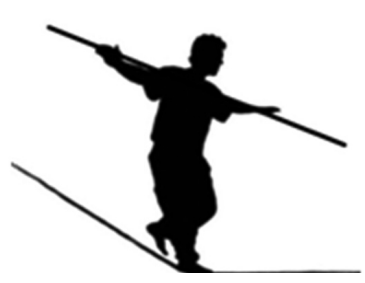

Medicine life must have a good play of balance. Funambulists think of certain strategies that would help ease out the tension when crossing. They use a balancing pole to attain that specific degree of symmetry. The pole helps to balance by lowering his or her center of gravity. A study by Schuster and associates [65] mentioned that certain methods to reduce stress by students often include effective time management, social support, positive reappraisal and engagement in leisure pursuits. Shaikh and colleagues [15] summed that the "prevalence of perceived stress seems to be high among medical students, which tends to affect not only their academic performances but also all aspects of their health. Review of academics and exam schedules, more leisure time activities, better interaction with the faculty and proper guidance, advisory services and peer counseling at the campus could do a lot to reduce the stress." It is important that one must find his center of gravity. Balance is the key to coping with the struggles in medicine. One must get the right amount of everything: sleep, fun, social, spiritual, and work, in order to function effectively. 


\section{Self-mastery Phase}
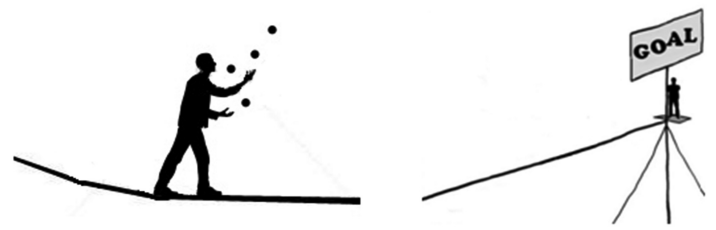

Once you get the hang of it, everything becomes easier and lighter. Medical students pride themselves with the ability to deftly multitask. They are efficient enough to deal and juggle with the overload of duties they are faced with. One does not need a dozen hands to do multitasking. One just needs two hands and a skill that is developed through constant and persistent practice. In the study by Melaku et al. [42], it was shown that as medical students progress in their year of study, the prevalence of stress decreases, possibly due to gradual adjustment to the learning environment and the usually declining failure rates in the later years of the course $[5,22,32$, $38,40-41]$. The highest prevalence of stress was observed among first-year students as they adapt to a new life, in a new environment, away from their family. Senior students, on the other hand, have developed their multitasking skills and are therefore better able to manage their studies and therefore better able to cope with stress than their younger counterparts.

Multitasking is, like almost anything else, an art that can be improved with practice. Balance, rhythm and focus are the key. The coordination of these three components molds a skillful juggler. This aptly applies to medical students: balancing work and rest, the timely rhythm of accomplishing one's errands and the depth of concentration one submits in executing a task [41]. Coping with stress in the Transactional Model can either be problem-focused or emotion-focused. The medical student can multitask, either to change the situation or change the way they react to the stress-inducing situation.
Similar to scaling the tightrope, juggling tasks in medical school adds strain to the whole process; but as soon as one gets the hang of it, one can see medicine in a different light.

\section{SUMMARY}

Often when people are faced with difficult or stressful situations, whether it be in medicine or other fields, they are almost always left wondering how to deal with them. From the words of an anonymous writer, "listen not to the voice without, but to the voice within, for here, recessed in your own mind, lies the answer to your future." The success and failure in dealing with academic stress depends upon the way we think or on the pattern of our thought. Stressors in medical school can evoke negative emotions which would sometimes feel overwhelming and where solutions seem elusive. However, the challenging situations in life are often the ones that offer the greatest opportunity for personal growth. Overcoming the challenges that life brings is never easy, but taking a long and honest look at the situations, experiencing and coping with the emotions they bring up and searching within oneself for the answers often brings surprising positive outcomes. Our respondents have experienced substantial challenges in medicine: they surmounted their inner trepidation; settled and acclimatized to their new surroundings; gained the courage to outwit stress and struggles; fought to strive, survive and stay focused; learned to maintain a state of balance and symmetry; and finally lived up to a sense of sovereignty and self-satisfaction. It is just a matter of perspective and attitude that demarcates a victor from a slacker.

The The world idly waits at their fingertips. They will someday heal the sick. For now, they are but few of the chosen ones to walk the tightrope in

the clouds.

Paraphrasing "On a Tightrope" (2007) 


\section{REFERENCES:}

1. Kaplan HI, Sadock BJ. Synopsis of psychiatry: Behavioral sciences clinical psychiatry. Williams \& Wilkins Co; 1988.

2. Asterita MF. The physiology of stress. New York, NY: Human Sciences Press; 1985.

3. Bisht AR. A study of stress in relation to school climate and academic achievement (age group 13-17). Kumaun University; 1980

4. Lal K. Academic stress among adolescent in relation to intelligence and demographic factors. American International Journal of Research in Humanities, Arts and Social Sciences. 2014 Feb; 5(1):123.

5. Firth J. Levels and sources of stress in medical students. $\mathrm{Br}$ Med J. 1986; 292:1177.

6. Styles WM. Stress in undergraduate medical education: 'the mask of relaxed brilliance'. British Journal of General Practice. 1993; 43:46-7.

7. Kaufman DM, Day V, Mensink D. Stressors in Ist-Year Medical School: Comparison of a Conventional and ProblemBased Curriculum. Teaching and Learning in Medicine: An International Journal. 1996 Jan 1;8(4):188-94.

8. Helmers KF, Danoff $D$, Steinert $Y$, Leyton M, Young SN. Stress and depressed mood in medical students, law students and graduate students at McGill University. Academic Medicine. 1997;72(8):708-714.

9. Supe AN. A study of stress in medical students at Seth GS Medical College. Journal of Postgraduate Medicine. 1998;44:1-6.

10. Ko SM, Kua EH, Fones CS. Stress and the undergraduates. Singapore Medical Journal. 1999;40:627-30.

11. Al Bedaiwi W, Driver B, Ashton C. Recognising stress in postgraduate medical trainees. Annals of Saudi Medicine. 2001;21(1-2):106-109.

12. Williams ES, Konrad TR, Scheckler WE, Pathman DE, Linzer $M$, McMurray JE, et al. Understanding physicians' intentions to withdraw from practice: the role of job satisfaction, job stress, mental and physical health. Health Care Management Review. 2001;26(1):7-19.

13. Carter AO, Elzubeir M, Abdulrazzaq YM, Revel AD, Townsend $A$. Health and lifestyle needs assessment of medical students in the United Arab Emirates. Medical Teacher. 2003;25(5):492-6.

14. Saipanish R. Stress among medical students in a Thai medical school. Medical Teacher. 2003;25:502-6.

15. Babar TS, Arsalan K, Muhammad K, Hamza K, Kiran N, Nadia AK, et al. Students, stress and coping strategies: A case of Pakistani medical school. Education for Health. 2004 Nov; 17(3):346-53.

16. Sherina MS, Rampal L, Kaneson N. Psychological stress among undergraduate medical students. Medical Journal of Malaysia. 2004 Jun;59(2):207-11.

17. Stecker T. Well-being in an academic environment. Medical Education. 2004;38:465-78.

18. Dyrbye LN, Thomas MR, Shanafelt TD. Systematic review of depression, anxiety and other indicators of psychological distress among US and Canadian medical students. Academic Medicine. 2006;81 (4):354-73.

19. Kjeldstadli K, Tyssen R, Finset A, Hem E, Gude T, Gronvold NT, et al. Life satisfaction and resilience in medical schoola six-year longitudinal, nationwide and comparative study. BMC Medical Education. 2006 Dec;6(1):48.

20. Sawa R, Phelan A, Myrick F, Barlow C, Hurlock D, Rogers $G$. The anatomy and physiology of conflict in medical education: a doorway to diagnosing the health of medical education systems. Medical Teacher. 2006;28(8):204-213.

21. Sreeramareddy CT, Shankar PR, Binu VS, Mukhopadhyay C, Ray B, Menezes RG. Psychological morbidity, sources of stress and coping strategies among undergraduate medical students of Nepal. BMC Medical Education. 2007,7:26.

22. Abdulghani HM. Stress and depression among medical students: a cross sectional study at a College in Saudi Arabia. Pakistan Journal of Medical Sciences Quarterly. 2008;24(1):12-17.

23. Ahmadi J, Kamel M, Ahmed MG, Bayoumi FA, Moneenum AA. Dubai Medical College students' scores on the Beck Depression Inventory. Iranian Red Crescent Medical Journal. 2008; 10:169-172.

24. Amr M, El-Gilany AH, El-Hawary A. Does gender predict medical students' stress in Mansoura, Egypt?. Medical Education Online. 2008;13:12.

25. El-Gilany $A H, A m r M$, Hammad S. Perceived stress among male medical students in Egypt and Saudi Arabia: effects of sociodemographic factors. Annals of Saudi Medicine. 2008;28(6):442-8.

26. El-Gilany AH, Amr M, Awadalla N, El-Khawaga AH. Stress among medical and law students in Mansoura, Egypt. Middle East Journal of Family Medicine. 2008,6(9):3 1-36.

27. Schmitter M, Liedl M, Beck J, Rammelsberg P. Chronic stress in medical and dental education. Medical Teacher. 2008;20(1):97-9.

28. Voltmer ER, Kieschke U, Schwappach DL, Wirsching $M$, Spahn C. Psychosocial health risk factors and resources of medical students and physicians: a cross-sectional study. BMC Medical Education. 2008;8:46.

29. Ahmed I, Banu H, Al-Fageer R, Al-Suwaidi R. Cognitive emotions: Depression and anxiety in medical students and staff. Journal of Critical Care. 2009;24:e1-e18.

30. Deborah G, Thompson D, Takeshita J, Beach C, Bryson P, Ephgrave K, et al. Depressive Symptoms in Medical Students and Residents: A Multischool Study. Academic Medicine. 2009;84:236-41

31. Dyrbye LN, Thomas MR, Harper W, Massie FS Jr, Power $D V$, Eacker A, et al. The learning environment and medical student burnout: a multicentre study. Medical Education. 2009;43(3):274-82.

32. Haglund ME, aan het Rot M, Cooper NS, Nestadt PS, Muller D, Southwick SM, et al. Resilience in the third year of medical school: a prospective study of the associations between stressful events occurring during clinical rotations and student well-being. Academic Medicine. 2009 Feb $1 ; 84(2): 258-68$

33. Jaykaran P, Yadav P, Bhardwaj A, Panwar, Chavda N. Perception of faculties regarding the stress in medical education - a qualitative study. The Internet Journal of Epidemiology. 2009;7(1)

34. Stucky ER, Dresselhaus TR, Dollarhide A, Shively $M$, Maynard G, Jain S, et al. Intern to attending: assessing stress among physicians. Academic Medicine. 2009; 84(2):251-7.

35. Elzubeir MA, Elzubeir KE, Magzoub ME. Stress and Coping Strategies among Arab Medical Students: Towards a Research Agenda. Education for Health. 2010;23:355.

36. Mannapur B, Dorle AS, Hiremath LD, Ghattargi CH, Ramadurg U, Kulkarni KR. A study of psychological stress in undergraduate medical students at SN Medical College, Bagalkot, Karnataka. J Clin Diagn Res. 2010 Aug;4:2869-74. 
37. Shah M, Hasan S, Malik S, Sreeramareddy CT. Perceived stress, sources and severity of stress among medical undergraduates in a Pakistani medical school. BMC Medical Education. 2010;10:2.

38. Yusoff MSB, Abdul Rahim AF, Yaacob M. Prevalence and sources of stress among Universiti Sains Malaysia Medical Students. The Malaysian Journal of Medical Sciences: MMS. 2010;17(1):30-37.

39. Brahmbhatt KR, Nadeera VP, Prasanna KS, Jayram S. Perceived stress and sources of stress among medical undergraduates in a private medical college in Mangalore, India. Int J Biomed Adv Res. 2013;4:128-36.Abdallah AR, Gabr HM. Depression, anxiety and stress among first year medical students in an Egyptian public university. International Research Journal of Medicine and Medical Sciences. 2014 Feb;2(1): 11-9.

40. Siraj HH, Salam A, Roslan R, Hasan NA, Jin TH, Othman $M N$. Stress and its association with the academic performance of undergraduate fourth year medical students at Universiti Kebangsaan Malaysia. The International Medical Journal Malaysia. 2014;13(1):19-24.

41. Melaku L, Mossie A, Negash A. Levels and sources of stress in medical students. Journal of Biomedical Education. 2015.

42. Satheesh BC, Prithviraj R, Prakasam PS. A study of perceived stress among undergraduate medical students of a private medical college in Tamil Nadu. Int J Sci Res. 2015;4:994-7.

43. Anuradha R, Dutta R, Raja JD, Sivaprakasam P, Patil AB. Stress and stressors among medical undergraduate students: A cross-sectional study in a private medical college in Tamil Nadu. Indian J Community Med. 2017;42:222-5.

44. Lazarus R, Cohen J. Environmental Stress. Human Behavior and Environment. 1977:89-127.

45. Antonovsky A, Kats R. The life crisis history of a tool in epidemiological research. Journal of Health and Social Behavior. 1967 Mar; 1:15-21.

46. Cohen F. "Coping" In: JD Matarazzo, SM Weiss, JA Herd, NE Miller, SM Weiss (eds.), Behavioral Health: A Handbook of Health Enhancement and Disease Prevention. New York: Wiley. 1984;

47. Davidsen AS. Phenomenological Approaches in Psychology and Health Sciences. Qualitative Research in Psychology. 2013;10(3):318-39.

48. Schwandt TA. Three epistemological stances for qualitative inquiry: Interpretivism, hermeneutics, and social constructionism. Handbook of Qualitative Research. 2000;2:189-213.

49. Smith JA, ed. Qualitative psychology: A practical guide to research methods. Sage; 2015 Apr 21.

50. Smith JA, Flowers P, Larkin M. Interpretative Phenomenological Analysis: Theory Method and Research. London: Sage. 2009;
51. Smith JA. Evaluating the contribution of interpretative phenomenological analysis. Health Psychology Review. 2011 Mar 1;5(1):9-27.

52. Husserl E. Logical Investigations. Routledge. 2012 Nov 12;

53. Rossman GB, Rallis SF. Learning in the field: An introduction to qualitative research. Sage. $2011 \mathrm{Jul} 7$;

54. Heidegger, M. Being and Time. Blackwell, Oxford. 1962;

55. Holstein J, Gubrium J. Phenomenology, ethnomethodology, and interpretive practice. Handbook of Qualitative Research. 1994:267-72.

56. Van Manen M. Researching lived experience: Human science for an action sensitive pedagogy. Routledge; 2016 Jun 16.

57. Patton MQ. Qualitative evaluation and research methods. SAGE Publications; 1990.

58. Polkinghorne D. Narrative configuration in qualitative analysis. International Journal of Qualitative Studies in Education. 1995;8(1):5-23.

59. Polkinghoime DE. Psychological inquiry and the pragmatic and hermeneutic traditions. Theory \& Psychology. 2000 Aug; 10(4):453-79.

60. Squire C. Reading narratives. Group analysis. 2005 Mar; 38(1):91-107.

61. Nygren L, Blom B. Analysis of short reflective narratives: a method for the study of knowledge in social workers' actions. Qualitative Research. 2001 Dec; 1 (3):369-84.

62. Levine RB, Cayea D, Shochet RB, Wright SM. Case study: A midclerkship crisis-Lessons learned from advising a medical student with career indecision. Academic Medicine. 2010 Apr 1; 85(4): 654-9.

63. Tight Rope [Internet]. Lucas Holtom Carnival. Available from: http://www.lucasholtomcarnival.com/carnivalday/index. $\mathrm{php} /$ rides-a-attractions/sports-arena/item/34-tight-rope

64. Schuster TL, Kessler RC, Aseltine RH. Supportive interactions, negative interactions, and depressed mood. American Journal of Community Psychology. 1990 Jun 1;18(3):423-38.

(c) Open Access This article is licensed under a Creative Commons Attribution 4.0 International License, which permits use, sharing, adaptation, distribution and reproduction in any medium or format, as long as you give appropriate credit to the original author(s) and the source, provide a link to the Creative Commons license, and indicate if changes were made. The images or other third party material in this article are included in the article's Creative Commons license, unless indicated otherwise in a credit line to the material. If material is not included in the article's Creative Commons license and your intended use is not permitted by statutory regulation or exceeds the permitted use, you will need to obtain permission directly from the copyright holder. To view a copy of this license, visit http://creativecommons.org/licenses/ by/4.0/. 